\title{
From Design to Management of Digital Epistemic Games
}

Lahcen Oubahssi $^{1}$, Claudine Piau-Toffolon ${ }^{2}$, Guillaume Loup ${ }^{3}$, Éric Sanchez ${ }^{4}$

${ }^{1,2}$ Le Mans Université, LIUM, EA 4023, Laboratoire d'Informatique de l'Université du Mans, Avenue Messiaen, 72085 LE MANS CEDEX 9, France, \{lahcen.oubahssi, claudine.piau-toffolon\}@univ-lemans.fr

${ }^{3}$ IBISC, Univ Evry, Université Paris-Saclay, 91025, Evry,France, guillaume.loup@univ-evry.fr

${ }^{4}$ Université de Fribourg, CERF - Rue P.-A. de Faucigny 2, 1700 Fribourg, CH, eric.sanchez@unifr.ch

\begin{abstract}
The development of pedagogies that can provide alternatives to traditional approaches is becoming increasingly important as a means of enhancing the attractiveness of training courses, appealing to new types of learners and designing learning systems that help to develop multidisciplinary skills. In this context, the JEN.lab project aims to offer innovative perspectives for learning based on the design of digital epistemic games (JENs in French). The research effort presented in this paper is part of the JEN.lab project. We aim to study problems related to the modelling and design of digital epistemic games. We propose a co-design process and an assistant tool supporting this process to guide teachers in designing digital epistemic games called ADDEGames (Assistance Design tool for Digital Epistemic Games). Our approach is based on: (i) the learners and the situation that emerges when they play the game, rather than the device used to play; and (ii) the teachers who want to manage a game-based learning situation. The iterative and participative development process and acceptance test using an agile approach are presented.
\end{abstract}

Keywords: JENlab, Game-Based Learning, Digital Epistemic Games, ADDEGames, Assistance Design Tool;

\section{Introduction}

The development of pedagogies that can provide alternatives to traditional approaches is becoming increasingly important as a means of enhancing the attractiveness of training courses, appealing to new types of learners and designing learning systems that help to develop multidisciplinary skills. In this context, the JEN.lab project [1] aims to offer innovative perspectives on learning based on the design of digital epistemic games (DEG, or JEN (stands for "jeu épistémique numérique" in French) [2][3] that foster epistemic interactions [4] supported by digital technology. The JEN.lab project also offers an alternative to the usual serious game approach, from an educational perspective (immersion in complex and authentic situations rather than interactions with a video game) and from a technological perspective (relying on mixed reality rather than a baseline modelled from a computational point of view).

Learning is a domain of design that is both complex and challenging [5]. Teaching is a design activity that can be considered "the intelligent center of the whole teachinglearning lifecycle", and which is open to transformation by the learners [6] and supported by process and tools [7]. Bennett et al. [8] established learning design as a process, and 
highlighted the need for methods and tools that can help and give support to teachers in designing their own solution. Research studies of the design of pedagogical situations, and serious games in particular, aim to propose new methodological and technological tools to support the teacher's activities. Learning design is an integral part of the work that all teachers perform [6], and there is a shortage of relevant practical and conceptual tools to support the teacher in this design activity [9]. Strategies and tools to support this work have emerged over the past decade as a significant line of research and development in educational technology. These include tools for documenting designs, online repositories for sharing design ideas and technical specifications and authoring tools to support delivery [8][10].

A typical approach is based on a particular framework and involves content design, resource organisation, activity planning, interactions and mediations to induce and support the design and orchestration of learning situations. Proposals for models and authoring tools are partly adapted to teacher-designers as non-specialists in game design and computer science. Our approach follows this trend and aims to adapt solutions to learning situations based on JENs. JENs are based on digital technology and simulate a real context in order to offer the learner/player the opportunity to deal with the epistemic framework of a profession and a realistic context. When playing, the players are asked to solve complex, non-deterministic and multidisciplinary problems [11] [12] [13].

One of the main issues that emerged from the JEN.lab project is how to help teachers to design, implement and manage a JEN into their classroom. The JEN.Lab project aims to develop JENs using an iterative and participatory design method in the context of real schools (secondary education), and to provide guides and tools. The expected outcomes of the JEN.Lab project include the proposal of an innovative solution for implementing a play-based learning approach through (i) focusing on the learners and taking into consideration the situation that emerges as they play, rather than a specific artefact dedicated to play (i.e. play vs. game); and (ii) focusing on the teachers who want to implement and manage a play-based learning situation in their classroom (i.e. play management vs. game design).

In this paper, we describe the main results of the work dedicated to the modelling and the design of JENs. These results consist of a method (a process) and a tool called ADDEGames (Assistance Design tool for Digital Epistemic Games) dedicated to helping teachers design their own JEN. The method and the tool were elaborated following a design-based research (DBR) approach [14][15][16][17].

The results presented in this paper emerged during the development of two JENs that were designed as part of the project: the Rearth and Insectophagia games [18]. The codesign of the JENS was carried out during workshops involving teachers/trainers researchers and other stakeholders (such as game-designers). The project enabled to carry out three iterations ( 3 years) dedicated to the design, implementation and testing of the JENs. The co-design of the prototypes were documented and written reports describing them were produced. These reports were revised after each iteration. The prototypes were tested in realistic conditions (i.e. in ordinary secondary classes).

This article is structured as follows. In the next section, we introduce the concept of $J E N s$, their characterisation and the player-centred approach (i.e. a play-based learning approach). In section 3, we present the JEN.lab artefacts (two JENs and the JEN.Cards) developed during the project. In the fourth section, we present the adopted methodology: an iterative co-design process based on participatory design and a supporting environment called ADDEGames. Section 5 presents the development and user acceptance testing of $A D D E G a m e s$ tool. The efficiency of the co-design approach and the perspectives opened by this work are discussed in the conclusion of the paper. 


\section{Digital Epistemic Games}

Previous studies of game-based learning confirm that a game cannot be separated from the experience of its players and promote a model that considers the experience of the player rather than the game itself. In view of this, we focus on JENS and advocate for a player centred-approach [19].

\subsection{Definition of Digital Epistemic Games}

For many years, educational tools known as "epistemic games" have been researched. According to Collins and Ferguson [20], the term "epistemic games" is used to describe the activity of a scientific investigation. The term game refers to the rules and strategies that guide the learner's questioning on a subject. This approach is based on a disciplinespecific structure and epistemic model. Perkins [21] uses the term "epistemic game" as a model of reasoning to define characterisation, explanation and justification. Since a historian, a lawyer and a physicist may describe, explain or justify the same facts in very different forms, it is necessary for the learner to work with very different capacities and methods of reasoning.

To achieve this, Shaffer [3] proposed expanding the model of an epistemic game by limiting it not to a single science or discipline, such as physics or mathematics, but to a set of disciplines grouped around communities of practice. According to this author, an epistemic game suggests leading the reflection through the vision of a set of experts and by taking into account the specificities of each community. The objective of this pedagogical approach is to combine the benefits of two approaches that are usually in conflict. For decades, in school systems, one pedagogical approach has encouraged learning by doing while another has aimed to ensure that the learner has sufficient theoretical knowledge before starting practical work [22]. The curriculum or learning path and the theoretical concepts that are learned individually are not sufficient to enable the learner to propose an innovative solution for an interdisciplinary problem requiring compromise, as in a real situation. In addition, in order for the learner's idea to be accepted, it must be based on knowledge, know-how and business concerns. Internship training therefore attempts to prepare the learner for this kind of situation. Nevertheless, it is subject to certain limits. Internship can only start at the end of the training, and the tasks set for the learner are often secondary. No global thinking on the problem and all parameters of the solution envisaged are possible. Conversely, experiences in the virtual environment can be proposed at any moment of the training and can place the learner as close as possible to this kind of problem. A $J E N$ offers the possibility of creating playful situations that are subject to real constraints, within which learners can immerse themselves, and where teachers can follow their progress and offer support throughout this experience. The realism of the context relies on innovative technologies offering a variety of different interactions. A wide range of tools is proposed for collaboration and exchanges through a virtual platform. Indicators are embedded in the virtual environment that allow learners and teachers to track their progress in each activity.

In the context of the digital age, Shaffer wanted to experiment with this concept through new applications called JENs. In these educational role-playing games using digital media, learners are encouraged to think like professionals [23]. For example, by playing the game Land Science [24], the learner, as a member of an urban planning firm, takes decisions for the redeveloping of an entire neighbourhood. The main objective of the game consists of creating a city plan, which takes into account the expectations of several communities and to fulfill their needs in terms of employment, housing and pollution. Since the expectations of the different communities are very different, the player is expected to understand the needs of each community and to find compromise.

Clim@ction [25] an online multiplayer JEN about land-use management and sustainable development involves three different communities. During eight weeks, teams 
pag. 26

of students address a complex and non-deterministic problem. They design a project, based on real local data, for energy production. In this role play game, "international companies" specialised in green energy compete to convince "local authorities" and an "association of citizens" that they have the best project for energy producing.

Likewise a game like Digital Zoo [22] also leaves a lot of possibilities for students to design virtual walking creatures in a simulator. The players are encouraged to propose complex solutions based on biomechanical engineering and think like an expert. However, for the game Science.net [26] it is assumed that players are not experts and they play the role of a trainee journalist involved in reporting about scientific issues. They are expected, to develop critical thinking and their ability to organize ideas.

These games are based on 4 pillars (1) a realistic simulation of a context where players have to address a complex and non-deterministic problem close to reality, (2) a space for reflexivity where autonomous students have the freedom to take decisions and can assess the consequences of their choices (3) a space for creativity where they can imagine innovative solutions to the addressed problems, and (4) a space for learning where the players develop the skills, methods, knowledge and values of the professional role that is being played [26].

The realism of the context relies on innovative technologies offering a variety of different interactions. A wide range of tools is proposed for collaboration and exchanges through a virtual platform. Indicators are embedded in the virtual environment that allow learners and teachers to track their progress in each activity.

While the term "serious games" has very often been used in the literature in recent years, the term digital "epistemic game" is rarely used. In this sense, it can be assumed that some authors use the term "serious game" even if the game has epistemic characteristics. It therefore seems necessary to define the characteristics of serious games that allow them to be identified as JENs. We can consider a game to be a JEN if it has the following characteristics:

- It proposes the resolution of non-deterministic problems [25], as in Clim@ction, [27];

- It involves solving complex problems [22], as in Digital Zoo;

- It relies on multidisciplinary activities [28], as in Urban Science;

- It offers the learner a realistic and authentic context [25], as in Clim@ction; and

- It is based on an epistemic framework [3], meaning that the learner must conduct the activity using the skills, methods, knowledge and values of the professional role that is being played [26], as in Science.net.

It should be noted that all of these characteristics are present in the games mentioned as examples. However, the characteristics of each JEN may have varying degrees of importance; for example, with regard to multidisciplinarity, one game may be based on related disciplines such as language and history, while another may be based on programming, ecology and economics.

\subsection{Switching from Game to Play}

$J E N s$ are playful and authentic learning situations that lead learners to solve complex, interdisciplinary and non-deterministic problems. They allow students to develop their own ways of thinking and acting by designing and trying out their own solutions [3][4]. An important issue is the design of complex and authentic learning contexts that support the development of reliable and transferable skills, and in particular the ability to manage non-deterministic and ill structured problems [29], i.e. problems for which experts cannot find a consensus [30]. JENs therefore foster epistemic interactions between learners, or in other words, explanatory and argumentative interactions that play a role in the coconstruction of scientific knowledge [4]. Epistemic interactions involve various interactive processes such as explanations, the production of an articulated discourse, elaboration of meaning or clarification of views [31]. JENs aim to develop the learners' 
capacity to mobilise various resources (knowledge and skill sets) within a given context, as well as their ability to reorganise these resources and reflect on their approach. Thus, from a pedagogical point of view, JENs rely on a skills-based approach.

$J E N S$ also rely on digital technology. Firstly, in order to create authentic interactive learning situations, JENs use mixed reality technologies [32] to create simulations using virtual reality, or contextual and situated activities with augmented reality and tangible interfaces. Secondly, in order to support rich interactions and the co-construction of knowledge by learners, JENS also use mobile systems and collaborative platforms to allow the creation of flexible educational spaces and times. These pervasive and persistent technologies blur the boundaries of the learning situation, making it even more authentic and captivating. Finally, the playful dimension of JENs also helps to address the issues of the commitment, motivation, autonomy, perseverance and satisfaction of the players/learners.

\subsection{The Player Matters}

In his seminal book "Le Jeu", Henriot emphasised the importance of distinguishing the game as an artefact from its usage [33]. For Henriot, no game element can have ludic properties on its own, and play emerges from the interactions between a player and a game. In other words, play emerges from an intention, and depends on the lusory attitude of the players [34], i.e. their willingness to accept the rules of the game and to participate. Indeed, "to play a game is to follow its rules" [35]. Studies of game-based learning are typically focused on the characteristics of a particular game. We consider that the player matters, and as a result, we consider that a shift from a game-based to a play-based perspective is required. By recognising that a digital artefact is not interactive on its own, we can place emphasis on the situation designed alongside the game, and on the interactions that emerge from that situation rather than on the game itself. These interactions are worth considering. From a Piagetian point of view, we can consider that learning results from the adaptation of the learner to the game, and results from the interactions that emerge within a given situation. These interactions can be called epistemic interactions, and the expression digital epistemic play can be applied [2].

\subsection{The Teacher Matters}

The implementation of a game-based pedagogy is complex, and traditional approaches consist of providing teachers and educators with authoring tools allowing them to design new games or to adapt an already existing game to their teaching context. For example, APPLiq [36] allows teachers to visualise an existing game scenario, adapt it to their needs, and verify the consistency of this new scenario.

However, the role of the teachers is not limited to game design, as they also have to manage the classroom orchestration [10][37]. Thus, their role involves the introduction of the game to the students, so that they agree to play. A teacher may also act as a game master and can be involved in the assignment of rewards, if this does not take place automatically.

The success of a game, in terms of its adoption by teachers, demonstrates its relevance [10]. Another role taken by the teachers relates to the debriefing after the game session. Debriefing is expected to foster reflection and metacognition [19][38][37]. The importance and complexity of the teacher's role for game-based learning need to be taken into account and technological solutions should include support for dynamic classroom orchestration. 
During the project, 3 iterations were carried out using a design-centric research approach involving practitioners and researchers. Two JENs called Insectophagia and Rearth were designed (described in Section 3.1 below). These JENs were tested in real classroom contexts, and evolved over design sessions carried out in each year of the project. As part of the $D B R$ methodology of the project, the research team designed JEN cards to enable brainstorming sessions between JEN co-designers (discussed in Section 3.2), and an integrated system called "Play Management System" (PMS) to help teachers managing the JEN and tracking play situations. The PMS provides support of a play situation (learning context, game documents, game characteristics, special interactions, technological aspects) [18]. It supports rich interactions during the gameplay, the playful dimension of $J E N$ and teachers' needs for managing classrooms.

\subsection{Two Examples of JENs: Insectophagia and Rearth}

Within the JEN.Lab project, we designed Insectophagia and Rearth, two role-playing games dedicated to educational objectives. These games are designed to allow students to develop skills in various educational disciplines (e.g. biology, physics, geography, computer science and mathematics) and media literacy.

The Insectophagia JEN, which relates to the principles of sustainable development, was designed for five classes of learners between 15 and 17 years old (86 students). In the game scenario, the global objective for each team (consisting of three or four learners) is to create a start-up company specialising in insect-based food production. First, the team needs to choose the type of insect they want to farm, based on ecological and dietary properties and the information they have collected. Then, they need to find a suitable location to build their factory and to make the right investments in terms of energy sources (solar panels, wind turbines etc.). Finally, they need to come up with an innovative and appealing product for customers. The players use digital technologies and real-world settings related to the mission. The game lasts approximately seven weeks (18 hours) depending on the school. Rewards and points depend on how the players manage to deal with environmental, social and economic issues. As the game master, the teacher is responsible for introducing the different missions, rewarding the students, time-keeping and chairing a debriefing session.

The Rearth JEN was designed for two classes of learners between 16 to 17 years old (50 students), who follow a teaching program dedicated to science, technology, industry and sustainable development. The global objective of the game scenario consists of finding a new planet that is suitable for humans to settle on with respect to sustainable development, since Earth has become uninhabitable. The learners play the role of explorers approaching a potential new planet. They are distributed into guild communities of technologists, builders and energy specialists. Their first mission consists of programming an exploration rover in order to position sensors on the surface of the planet, while avoiding natural barriers, managing the batteries and dealing with unexpected sensor failures. In the second phase, the players analyse and share the data collected by the sensors on their allocated site. In the final phase of the mission, the players discuss and determine the most suitable site.

Although these JENS were both role-playing games dedicated to sustainable development education, 2 different teams designed them and they turned out to be very different in terms of game-play and educational content. However they both address complex and non-deterministic problems and students are expected to act as experts.

\subsection{JEN Cards Dedicated to JEN Design}


Before formalising the scenario of a $J E N$ in an authoring tool, we conducted co-design sessions involving teachers, researchers, educational engineers, game designers and developers. The experience acquired during these sessions allowed us to develop a set of cards for carrying out brainstorming sessions with JEN co-designers.

Collaborative design for JENS requires the different aspects of the game to be designed using a common language. Based on research works [23][39][40][25] that have highlighted the importance of tangible tools to design serious games, a specific card game named JEN.Cards was developed by the research team [11][12] to help designers to communicate and share their expertise. These cards, called JEN.Cards, were divided into five categories of social interaction, play, competence and technology cards [41], and an additional category was related to service tracking. Blank cards were also available to allow teachers to add features to the $J E N$ :

- Social interaction cards: enable the designer to choose the modalities for learners' interactions. For each activity, the designer must determine whether the learners will be alone, grouped in pairs, in teams or as a single group. In each of these cases, the designer is invited to specify the type of social mechanics that should be used, such as collaboration, competition or cooperation.

- Play cards: offer ways for the learner to be faced with chance, challenges and appreciation. The learner may also have a specific role in the activity, with different rules from the other participants. Some cards allow the designer to create situations in which the learner will feel out of control.

- Competency cards: define the expected learning outcomes, and visually represent the different skills, abilities and knowledge involved. The cards in this category are mostly specific to the game being designed, although some soft skills cards related to communication and project management can easily be reused from one game to another. We therefore needed to create these cards before the first design session with the teachers.

- Technology cards (Fig.1): help co-designers to make choices of technologies and interactions. They help in choosing the tools to be used to implement educational and play choices without requiring technical precision. The numbers of choices are important, and the technologies are therefore grouped according to their benefits, such as location, sharing, communication, etc. In addition, some technologies allow the learner to stay connected to the game after the sessions, while others allow switching to virtual learning worlds.

- Service tracking cards: define the information (types of trace) to be collected during or after the game sessions. Teachers define the type of data/traces (log, video, notes, etc.) they need to collect, their usage (learners' reflexivity, teacher's evaluation needs, etc.) and the type of visualisation (feedback, visual dashboard, etc.). 


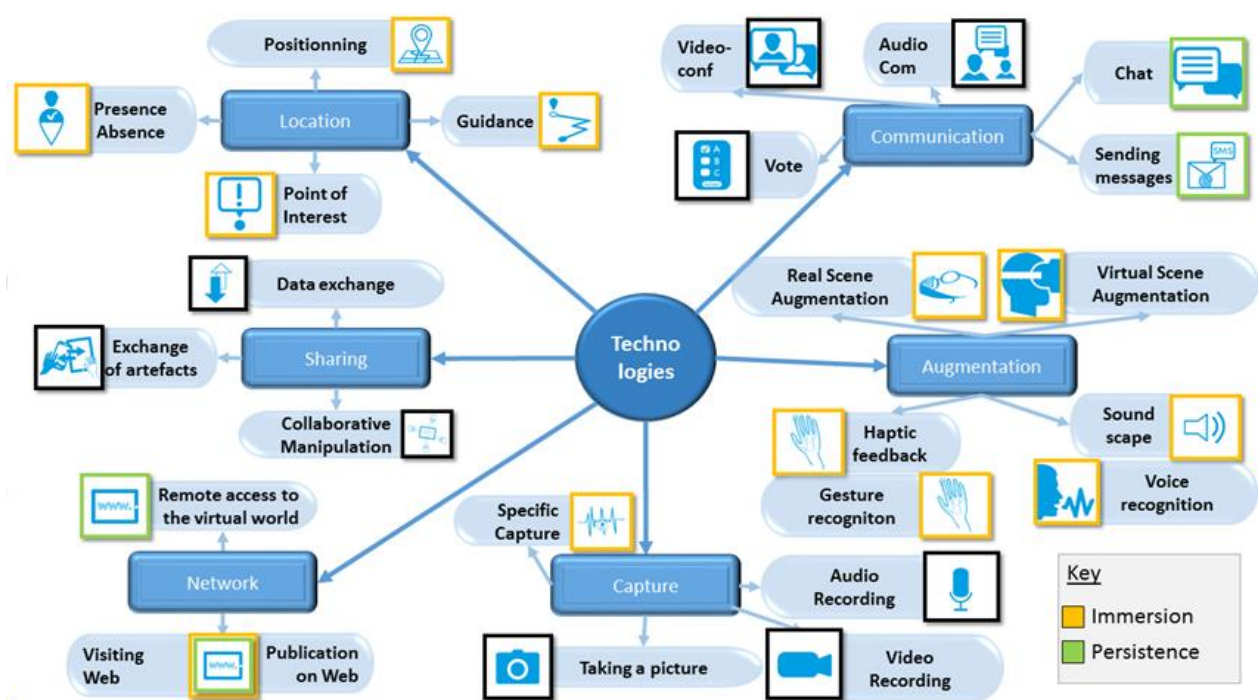

Figure 1. Overview of all technology cards [11]

No maximum number of cards is required to create a concept or a particular element of the game. The cards should be combined with more traditional creative materials and techniques such as post-it notes, erasable slates, storyboard cards, large sheets of paper, etc. Participants in these design sessions were encouraged to comment on their card associations by writing notes or scenario pieces. In addition to the JEN.Cards, "blank cards" were available to co-designers, and could be completed in their own words to facilitate dialogue between the different co-designers. Based on an analysis of the sessions dedicated to game design, we found that depending on the scenario, designers initially used those cards whose concepts they understood. They then used the other types of cards to complete their skills and explore the less developed dimensions in their game. We also found that JEN.Cards were able to foster collaboration among co-designers. However, pre-selection by the session facilitator is necessary, otherwise co-designers may be confronted with the analysis of hundreds of cards.

Our research question concerns co-design by people who have different skills and cultures. This context justifies the importance and the usefulness of formalizing the process and the tools necessary for this type of co-design work. JEN Cards and PMS are part of these tools used by teachers during the co-design of $J E N$ we established. Since the project is design-based, we carried out a collaborative process aiming at the co-producing of knowledge as specific designs and devices (ADDEGames), and models of such designs.

\section{Methodology}

Contemporary research into design in education suggests that a teacher's design practices should be iterative, with a design emerging before, during and after the implementation of a unit ([42][43] in Bennett et al. [8]) following a participatory approach [44][8]. This trend in design is consistent with design-centric research approaches in education. Mor and Winters [45], and Goodyear [6] argue in favor of design-based research [14][15][16][17], and the merging of research and practice. $D B R$ involves the participation of researchers and practitioners and requires guides and tools dedicated to support the design process. The methodology of the project follows an iterative and participatory design process, with alternating analysis and design phases, and is based on a design-based research (DRB) approach in order to produce pragmatic and theoretical knowledge. Teachers/trainers are involved from the outset as designers within the learning environment they intend to use, and pedagogical activity is inseparable from design activity [46]. Researchers collaborated with teachers/trainers in the first phases of 
the design process and helped to define and set up tools (artefacts and platform) for designing and managing JENs. The emphasis here is on the competencies of all the actors, and the user is integrated in the process and recognised as an expert, using a participatory approach [8][44].

\subsection{Design-Based Research}

$D B R$ is an iterative process carried out with the aim of designing educational artefacts such as techno-pedagogical devices or educational programs and their implementation at various levels (i.e. for formal learning, classroom activity, or interventions in school or curriculum). This design process is combined with an analysis of the results of these educational practices, which are carried out collaboratively by researchers and practitioners. $D B R$ has the following main characteristics [14]:

- Contributive: Research conducted in this way provides the opportunity to develop something new (innovative learning approach, innovative learning artefact, etc.);

- Collaborative: Stakeholders develop a common view of the educational objectives addressed by the project. They build an agreement for the design of innovative tools and a common understanding of the theoretical background needed for the development of these tools;

- Iterative: The design of the learning artefacts results from several cycles of prototype design and analysis, allowing flexible revisions to the design;

- Tested in realistic contexts: Experimental testing of the learning artefacts by practitioners in real contexts (schools) allow the designer to take into consideration the complexity of these contexts and to collect data for the analysis phase [47].

$D B R$ conceptualises researcher-practitioner relations through the notion that collaboration occurs through developing a shared discourse on practice [16]. This collaborative process encompasses design, implementation in real learning settings and data analysis, and allows the understanding of practitioners and researchers to evolve. In terms of developed knowledge, the results are both:

- Pragmatic: New practices are developed, new tasks performed, new technology employed; and

- Theoretical: The hypotheses embedded into the learning situations are confirmed or rejected, and the theoretical models are refined.

Thus, the methodology of this research work is based on the collaboration between practitioners (teachers) and researchers. The objectives are both pragmatic (producing innovative digital applications adapted to the teachers' expectations) and theoretical (developing new models for instruction and learning). As a result, the methodology is influenced both by the $D B R$ approach and participatory design from the field of humancomputer interaction [48]. In the field of technology-enhanced learning, $D B R$ has close relationships with software design methodologies that aim to take into account end users by integrating them into the early stages, such as agile methodologies [49] and usercentred methodologies [50]. This methodology has been applied in the design of the 2 JENs (Insectophagia and Rearth).

The collected data consists of the decisions taken by the multidisciplinary team in terms of game-design. The data takes the form of minutes, written reports, forms and other artefacts produced by the participants. The data are analyzed and enables for modelling both the JENs and the co-design process.

\subsection{DBR in practice}

Using the $D B R$ approach adopted in the JEN.lab project, researchers organised workshop design sessions for JENs throughout the project with researchers and teachers. These design sessions were dedicated to defining learning objectives, the game universe and the 
gameplay. A prototype was developed for each game and experiments were carried out in realistic conditions by the teachers involved in the design phase. Eleven design sessions [10] were carried out for Insectophagia and seven for Rearth, including researchers and teachers as co-designers, with the aim of defining the learning objectives, the game universe and the gameplay. Several students also participated and provided ideas for the game scenario, the teaser and the digital tools they found relevant. The game scenarios [51] imagined during these sessions were first modelled as "Player" Flow [10], and then defined in detail using LEGADEE (LEarning GAme DEsign Environment)[52]. This authoring tool is dedicated to learning game design, and enables the user to represent both the educational structure itself and the way this structure is integrated into the game scenario. $L E G A D E E$ also enables the designer to specify the targeted learning objectives, the learners' activities, specific rewards and the teachers' roles for each game level.

During the following cycles, the researchers suggested intermediate objectives and rules for the creation of a JEN. The final objective was to support the co-designers in the production of storyboards that could provide a basis for formalising the scenario. It was therefore essential to ensure that co-designers had better information about the pedagogical objectives and specificities of JENs. It was suggested that the co-designers should discuss the organisational and budgetary constraints that could impact the limits of the game. For example, if the teacher was not able to organise a specific activity (a field trip, a puzzle to be solved...), the technology localisation service JEN.Cards could be put aside for the rest of the procedure. Similarly, limits on the number of hours for classes and the number of learners allowed us to establish a benchmark for the choice of activities during the subsequent phases.

It was then suggested that the co-designers should write a short synopsis in order to define a scenario context associated with the social interaction, play, skills and technology cards. Following the design phase, we developed a prototype for each game. The Insectophagia prototype was a mix of paper-based and digital activities. The main structure of the game was paper-based (e.g. paper cards, tokens representing points, a game booklet) while periodic activities were completed on computers (information research, outdoor activities involving the collection of data, preparation of a presentation, commercial announcements, etc.). In contrast, Rearth was mainly based on digital artefacts (e.g. an online comparison score chart, a chat system, a virtual reality spaceship) including periodic paper-based activities (e.g. a final discussion to choose the most suitable planet).

Each game prototype was tested in realistic conditions by the teachers involved in the design phase. After the experimentation, two sessions, with both designing teams, were organized to discuss the lessons learned from the experimentation of the JENs. From the teachers' point of view, both games were valuable for students, since they were immersed in a complex situation in which they needed to collaborate and to mobilise various resources. However, the pedagogical situations emerging from these games were not easy to manage in real time in the classroom. For instance, in Insectophagia, the teachers underlined the importance of support for managing the points earned by the different teams. They also had difficulties in sequencing the activities and applying the flow chart defined during the design sessions. They expressed a need for a tool dedicated to managing the rules and other game elements (such as using event cards at the right time).

In Rearth, the emerging requirements were different. This digital game focused on creating a persistent fictional world in which students conducted simulations and tested hypotheses. To ensure the persistence of the world, the game master sustained the game through information sent via email to each student. This task could be performed more easily with support from a digital tool that could help to manage these laborious tasks.

Researchers and practitioners involved in the design expressed the need for being creative and, at the same time, respecting the main characteristics of a JEN. Thus, they required a tool to help them to organise the activity and to guide them. We developed a co-design process and the ADDEGames tool to support it [53] to help teachers and game designers to design a JEN (as described in Section 5). 


\section{Toward a Co-Design Process of JENs}

The main contribution of this work is the proposal of a co-design process and the $A D D E G a m e s$ tool to help, guide and support teachers in activities related to the design of a $J E N$. This process emerged from the work carried out during the project. It is iterative and collaborative, and involves all the actors in the design project. It is composed of a set of phases and steps to help and guide the members of a multidisciplinary team involved in the co-design of a $J E N$ according to their expectations in terms of learning goals and gameplay. This process allows the designers to quickly establish a detailed specification and to easily develop a $J E N$, taking into account the constraints faced by practitioners. However, this guide (process) is not intended to provide steps or methods for establishing the graphic style of the JEN. This process emerged from specific workshops dedicated to the modelling of Insectophagia and Rearth. During these workshops, we identified the different tasks to be performed by the team and the encountered difficulties. During these workshops, the co-design was supported by design forms during the different phases and stages defined by the JEN.Cards (section 3.2). Fig. 2 illustrates the six main phases in the proposed process. 


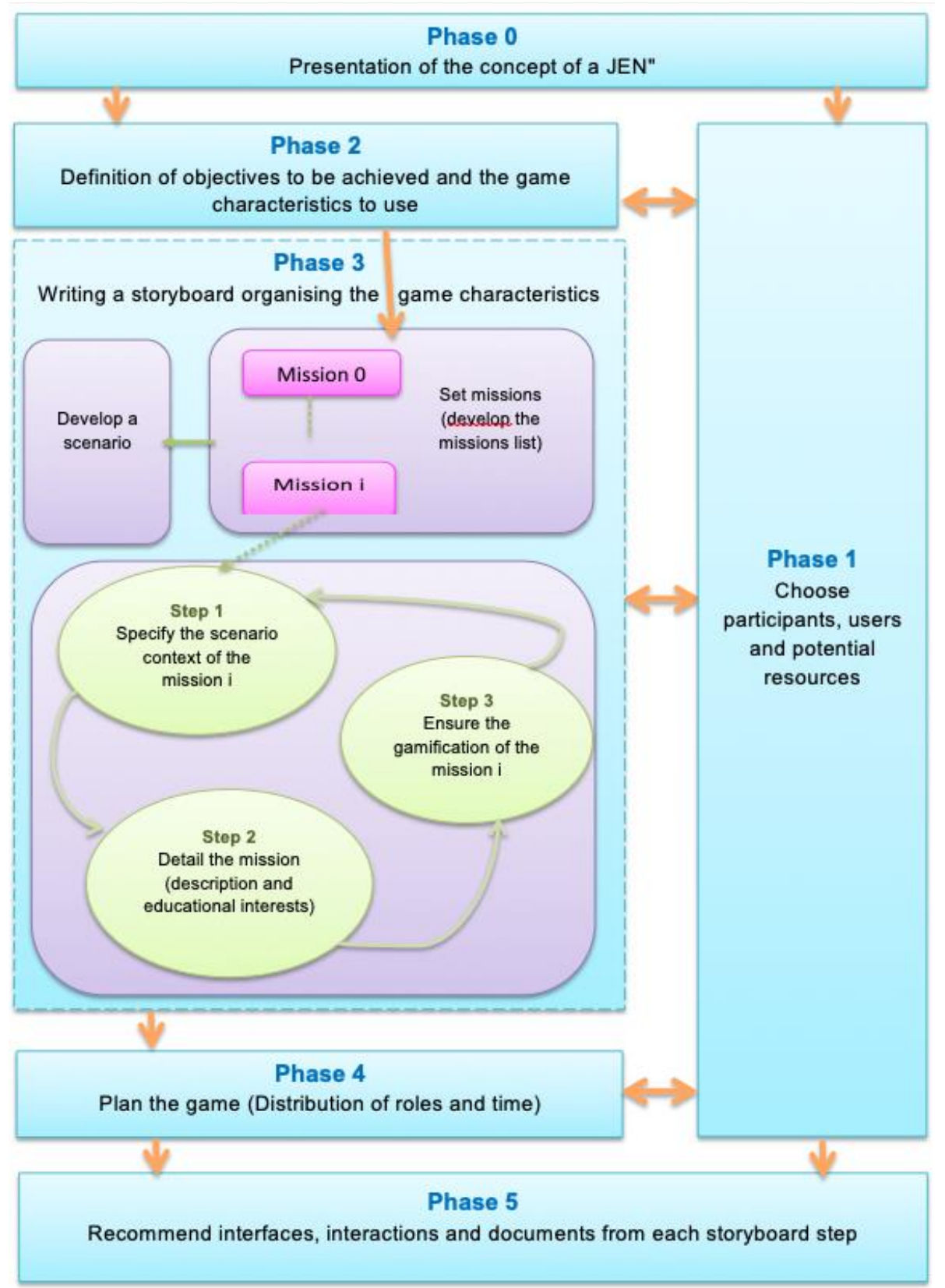

Figure 2. The six main phases of the proposed process

Phase 0: The objective of this phase is to discuss the concept of a JEN within the team who would like to realise their first JEN (its objectives, its characteristics and the constraints involved; see Section 2.1). We note that during all of the phases of the design process, the participants may use the different categories of JEN.Cards (Table 1) as established with the actors involved in the design session (if necessary, they can add new categories of cards or new cards in a given category). JEN.Cards cover all the dimensions and characteristics of epistemic games in order to facilitate exploration and creativity by designers.

Phase 1: The objective of this phase is to allow the participants to define who will participate in or use the JENS, and to identify potential resources to be used when they play. The characteristics of the JENS that should be validated in this phase are the number of players/learners, the duration and the number of sessions, and the tools and devices (or platforms) that can be used. In this first phase, the teacher needs to choose (filter) the technology cards according to the devices that can potentially be used. By example, the Rearth game requires 2 teachers, 4 groups of 15 students, 8 hours maximum for each 
group, 2 classrooms with 15 computers and a budget for the purchase of new equipment (virtual reality headsets, computers, etc.).

Table 1. Characteristics of a JEN and the Design Phase [54]

\begin{tabular}{|c|c|c|c|c|c|}
\hline $\begin{array}{l}\text { DEG } \\
\text { Features }\end{array}$ & $\begin{array}{c}\text { Competencies } \\
\text { /Skills }\end{array}$ & Play & Technology & $\begin{array}{c}\text { Social } \\
\text { Interaction }\end{array}$ & $\begin{array}{c}\text { Service } \\
\text { Tracking }\end{array}$ \\
\hline Phase 1 & $\begin{array}{c}\text { Multdisciplinarity } \\
\text { Number of } \\
\text { players/learners } \\
\text { Duration of the session } \\
\text { Number of sessions }\end{array}$ & & $\begin{array}{l}\text { Devices or } \\
\text { Platforms } \\
\text { Tools }\end{array}$ & & \\
\hline $\begin{array}{l}\text { Phase } 2 \\
\text { Step } 1 \\
\text { Step } 2\end{array}$ & $\begin{array}{c}\text { Multdisciplinarity } \\
\\
\text { Epistemological } \\
\text { Framework } \\
\text { C.ommunity of Practice }\end{array}$ & & 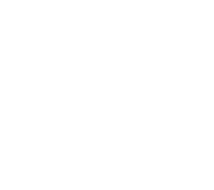 & - & \\
\hline $\begin{array}{l}\text { Step } 3 \\
\text { Step } 4\end{array}$ & $\begin{array}{l}\text { Authenticity } \\
\text { Skills covered }\end{array}$ & * & $\begin{array}{c}{ }^{*} \text { (Communication } \\
\text { services, Sharing } \\
\text { services })\end{array}$ & $\begin{array}{l}\text { Configuration } \\
\text { Type of } \\
\text { interaction }\end{array}$ & * \\
\hline $\begin{array}{l}\text { Phase } 3 \\
\text { Step } 1 \\
\text { Step } 2 \\
\text { Step } 3\end{array}$ & $\begin{array}{c}\text { Authenticity } \\
\text { * }\end{array}$ & & * & * & $*$ \\
\hline Phase 4 & Duration of the session & & $\begin{array}{l}\text { Devices or } \\
\text { platforms }\end{array}$ & & \\
\hline Phase 5 & & & & & \\
\hline
\end{tabular}

* : all features are concerned

Phase 2: The objective of this phase is to define the expected learning outcomes and the characteristics of the game to be played. It consists of four steps (Fig. 4):

- In the first step, the teacher must define the disciplines involved in the game (at least two disciplines). The purpose of this stage is to briefly define the main disciplines in order to write an adapted synopsis. The characteristic of the JEN that is validated in this step is its multidisciplinary feature. In the case of the Rearth game, the main disciplines involved were computer programming and sustainable development.

- For the second step, the teacher chooses the communities and professions to which the players belong. It is expected that the player will play, as a community member in order to share skills, know-how and interests, and an expert community is needed in the disciplines elicited in the first step. The characteristics of JENS that are validated in this step are the epistemic framework and community of practice. Builders, energy specialists, technologists or cyberneticists were identified as communities of practice for the Rearth game.

- At the third step, the teacher, the researchers and game designers write the narrative of the game. The objective is to define the context in which the script is registered. The scenario must be defined as a plausible/realistic story. The characteristic of JENs that is validated in this step is the authenticity. The figure 3 illustrates the Rearth synopsis. 


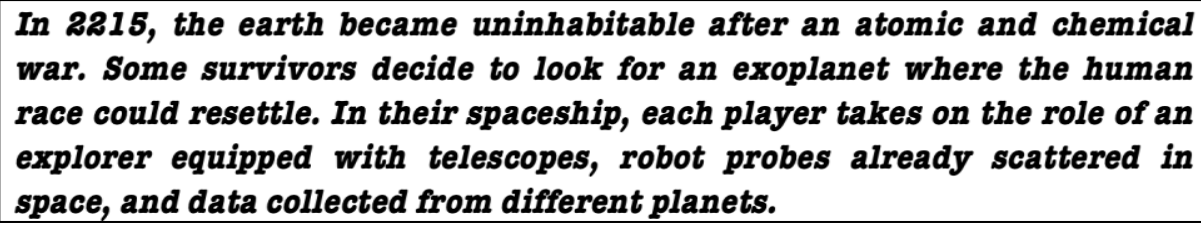

Figure 3. The Rearth synopsis

- For the fourth and final step, the participants define the characteristics of the game. The objective is to pre-select the concepts that should be included from an educational perspective. Numerous characteristics of JENs are validated in this phase (Table 1). The main constraints to be respected are the choice of at least two cards from each category (competencies, play, technology, social interaction, service tracking), and several examples of an activity related to each competency should be elicited. For Technology, the choice of at least one card from "communication services" and one from "sharing services" is required. For "Social interaction", the choice of at least one card for the type of interaction should be done. For the Rearth game, the participants focused on analysis and collaboration competencies (analysis of planet's resources, managing existing code, searching for the best strategy and tools adapted to the situation, collaborate effectively within a group). Remote control of the robot and sending of automatic emails during the game play are examples from the technology category. The main social interactions were dedicated to individual and collaborative activities.

At this phase, the participants may use the JEN.Cards to define the concepts to use in their game, and in particular to identify the educational interest and the playful springs. Many characteristics of JENs are validated during this phase, including the epistemic framework (the authenticity of interactions within the gameplay), the multidisciplinary aspects of all the steps, if the problem is complex and non-deterministic (or at least for the final task), and social interaction (configuration, categories of games mechanics).

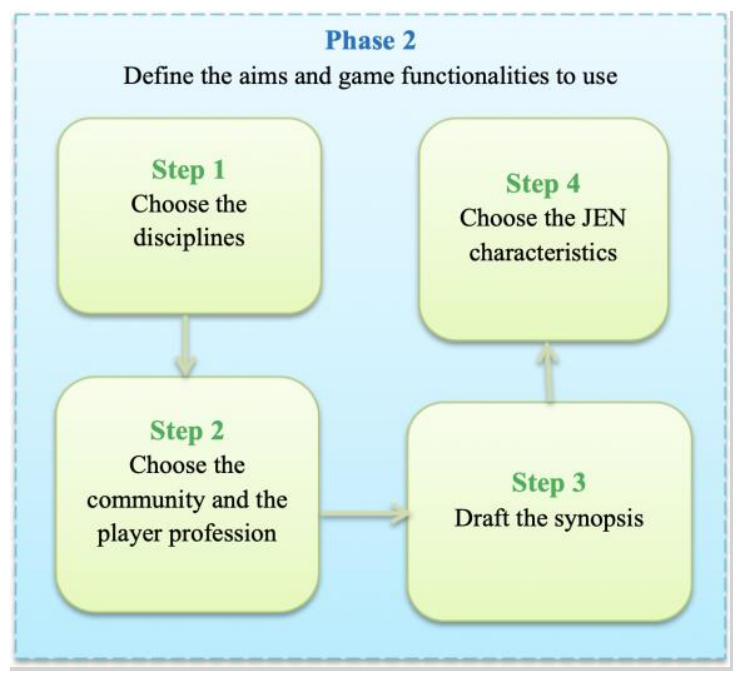

Figure 4. The four main steps of Phase 2

Phase 3: This phase consists of writing a storyboard based on the choices made during the previous phase (phase 2). During this phase, the co-designers try to develop a coherent storyboard, specify all the missions of the game and define the authenticity of the interactions in the pedagogical situation. It consists of three steps: 
- At the first step, the co-designers identify the different missions or steps of the game. The characteristic of $J E N s$ that is validated at this step is the authenticity of the interactions according to the topic addressed by the game (Fig. 6).

- At the second step, the participants specify the context for each mission, its description, the educational purpose and the game features. They define the different levels of the game and ensure its adequacy in regards to the educational objectives. The participants faced the following constraints: associate a characteristic (competence and social), and include at least one activity per team of players. Different tools and supports can be used by the participants (storyboards, the competency and social cards, etc.). The main characteristics of $J E N S$ to be validated during this step include multidisciplinarity and the inclusion of a complex and non-deterministic problem.

- At the third and last step, the participants finalise the overall scenario, and specify the overall context, the description, the pedagogical interest and gamification. Correlation with the initial objectives must be ensured. The data to be collected for the learners, the teachers and the researchers are defined. At this step, the participants use storyboards, and the play and technology cards.

Different JENs characteristics are validated during this phase, for example the epistemic framework (the authenticity of interactions in the situation), the multidisciplinary features of all the steps, a complex and non-deterministic problem (at least for the final task), and social interactions (configuration, type of mechanics).

For the Rearth game, the teachers defined a mission and its objective (Fig. 5). By example one of the activities of the mission was the exploration of the probe robots. This activity needs individual and collective tasks. The program should be tested before submitted to the robot. It should be possible to visualise the robot in action in real time (Fig. 7).

The spacecraft is in orbit around the new planet. The objective of the mission will be to identify the most suitable site. The objective is to measure the viability and the presence of resources necessary for the settlement of humans. For this, very basic satellite information has already made it possible to identify the best terrains on the planet. A robot has already been sent to each.

Figure 5. Rearth: Mission 3 and its objective

Possibility to visualize the robot achieving his program in real time on the ground. Some areas will be hided.
They can potentially hide an obstacle. The robot transit path through these areas could stopped the
program (Play).
The program can be simulated (without taking account constraints) before execution. It would be possible
to stop the program execution but it would not be possible to reinitialize the game.
Immersion: It would be possible to visualize with the help of an Virtual reality helmet (Oculus Rift 2 ) the
robot in action on the ground (Realism).
The program will be continued between classrooms session. The player will receive email once the program
finished.(Persistence)

Figure 6. Rearth (Mission 3,Task 1): Probe robot exploration scenario 
pag. 38

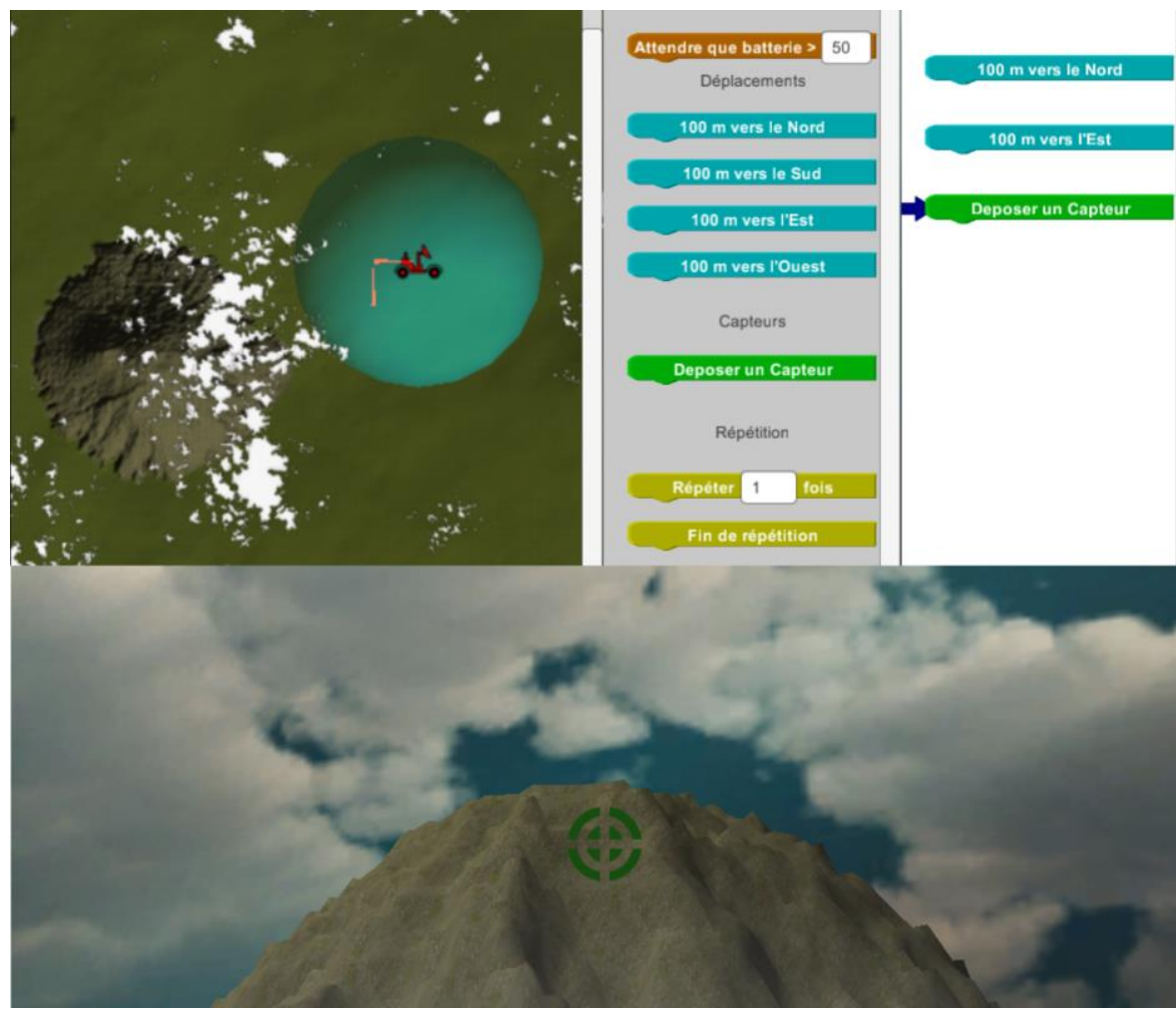

Figure 7. Programming interface of the probe robots in Rearth JEN

Phase 4: This phase consists of specifying the role of each actor within the game, and allocating time for each game mission (taking into account the maximum duration set in Phase 1 of the process). The characteristics of JENS that are validated in this phase are the duration of the session and the devices (or platforms) to be used. The PMS was used for this phase. For instance of the PMS dedicated to the Rearth JEN, we identified a Mission block. This block enables to access to the different phases of the current mission and to the relevant dedicated tools (Fig. 8). For all of the phases a forum enables to communicate with the different community of practice (guilds). Specific tools like document repository are available for some phases of JEN (data analysis or guilds part).

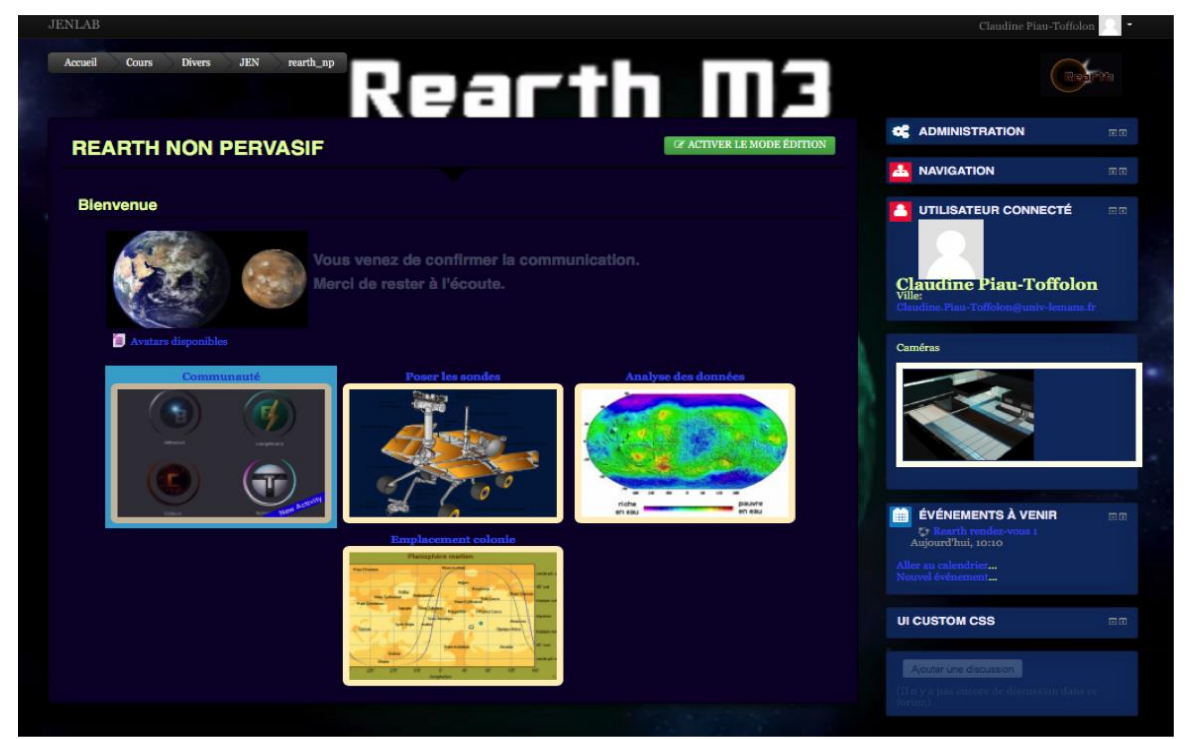

Figure 8. Teacher's PMS interface for Rearth game 
Phase 5: This phase is dedicated to identify the recommendations for choosing interfaces, the interactions, and the documents for each storyboard step. No specific features of JENs are involved.

For each phase, we define a set of objectives and constraints that are related to the phase and which validate the characteristics of the JEN. We summarise these constraints in a form filled out by the co-designer. To help the participants to take ownership of this process and better design their JENs, we developed the ADDEGames environment. We present this environment in the following section.

\section{ADDEGames: A Design Assistive Tool for Digital Epistemic Games}

In the previous sections, we expressed the need for a specific conceptual context to promote JENs. We also argued that there is not yet an existing model that explicitly describes the elements of a co-design process for JENs. Hence, in the following section, we propose such a model based on the ideas that emerged during the work dedicated to the design of the JENS. We describe this model (Section 6.1) in order to provide a first insight before presenting the authoring tool ADDEGames, a tool dedicated to support the co-design process (Section 6.2).

\section{$6.1 \quad J E N$ Model}

Designing a $J E N$, implies to conceive a social, collaborative and open scenario. In order to be open, a scenario should be adaptable by different actors such as learners, teachers or external actors. Thus, an open scenario consists of a variety of concepts categorised into static, non-adaptable (fixed) and dynamic types, which may be adaptable according to the learner's preferences.

Before developing the ADDEGames environment [55], we initially developed a JEN model based on the two examples of JEN modelled during the co-design workshops (Section 3.1). The analysis of the outcomes of the different co-design workshops and the development of the co-design process allowed us to identify the different pedagogical concepts underlying the two examples of JENs. We group these concepts into a model called the JENs model. Our aim is to identify the educational language embedded in the $J E N s$ and to develop a conceptual model for an environment that supports the JEN codesign process. Fig. 9 illustrates the main concepts of our model:

- A JEN consists of one or more missions or levels, each of which is associated with one or more working sessions, one or more educational interests and one or more playful springs.

- There may be one or more learning scenarios in a work session.

- A $J E N$ is associated with at least two communities and two disciplines.

- The main users of JENs are teachers and learners, although other external actors may also be involved.

- Finally, we note that the use of JEN.Cards is an essential element to help teachers to model JENs, and especially the educational interests and playful springs. 


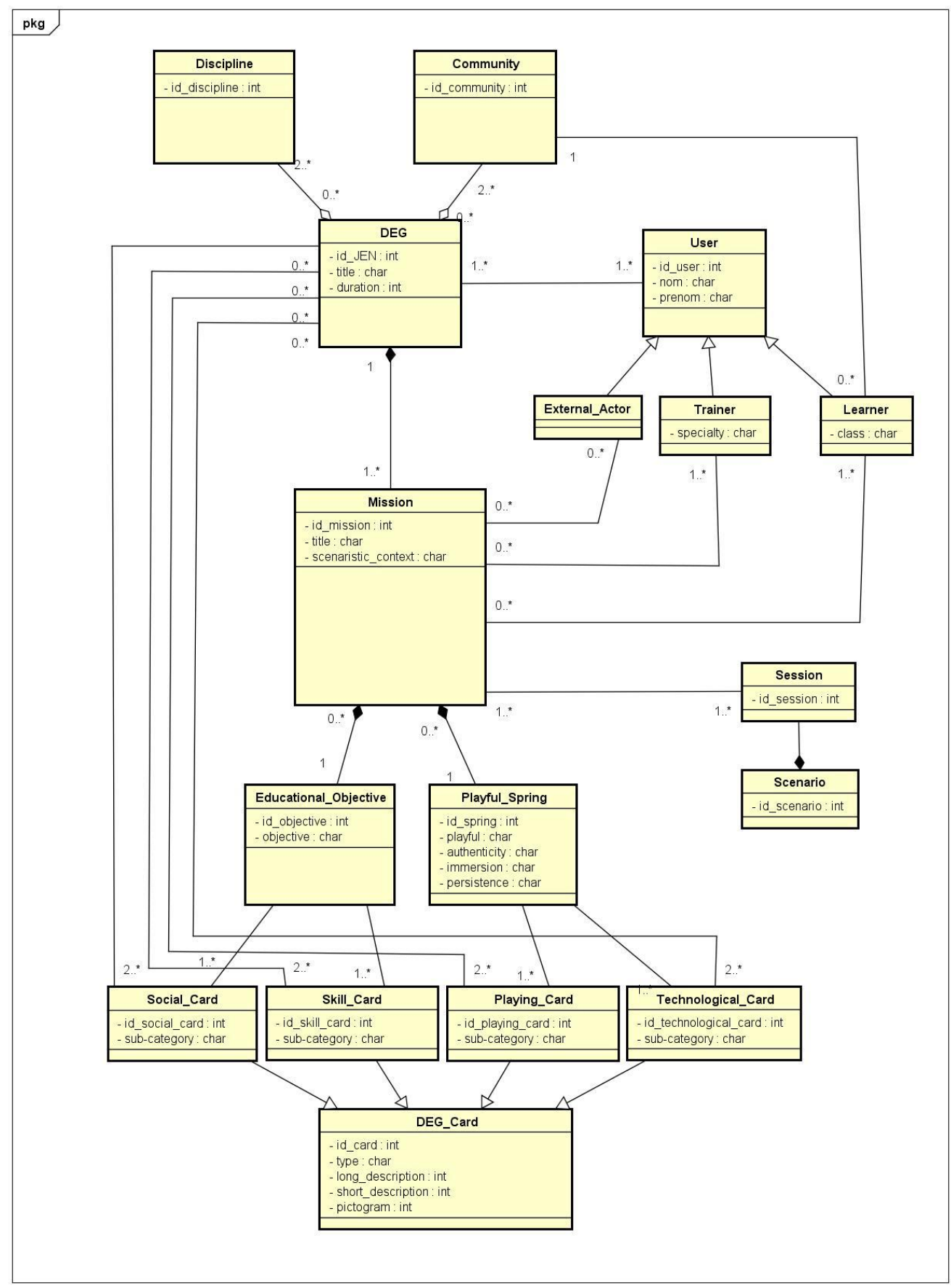

Figure 9. The JEN model

\subsection{The ADDEGames Architecture}

The first objective of the ADDEGames authoring tool is to help teachers/designers (who do not have the knowledge required to design a JEN) to define the initial design of a JEN. We note that $J E N S$ are dynamic, meaning that they change as they progress. Thus, the purpose is to allow a team of teachers to establish the initial blocks of the JEN, and to facilitate its evolution. The second objective is therefore to give teachers/designers the opportunity to evolve their initial design and/or adapt an existing JEN. They can design these games using the $J E N$ model, which provides them with a methodological framework to describe the learning activities and their organisation using a visual tool. The third objective is to validate our co-design process. We note that the ADDEGames architecture 
is the result of a set of scenarios described during the design workshops. Its characteristics include the following:

- It offers an environment to help teachers to easily design their $J E N$;

- It allows the designer to model a new JEN or to adapt existing JEN models;

- It allows the designer to generate a specification that includes different design elements of JENs.

The administration module is dedicated to customize the platform and to manage users accounts, the resources needed for JENs design. The main functionalities of this module are: user profile management, backup and restore data, and JEN terminology configuration. We note that, depending on the needs of teachers and their pedagogical context, the concepts used to model a JEN are not the same. Terminology is used to describe these concepts. The administration module enables to set the terminology choices according to the teachers' needs.

The teacher module is dedicated to help teachers to design their JEN as easily as possible. The main functionalities of the teacher module are as follows:

- The JEN management function allows the designer to create a new JEN by specifying its title, description, and the users who are participating in the modelling. It also enables the designer to edit, display or delete an existing $J E N$ or to share it with other users of the tool.

- The editing function allows the designer to model the game using the five main phases that constitute our co-design process. For example, in Phase 1, the co-designers can specify the number of teachers, learners and actors who will participate as players or game masters, the duration, the number of sessions, the tools and the devices that will be used during the game. Phase 2 allows the designer to specify disciplines, communities, a synopsis, etc. In Phase 3, the missions/levels of the game are defined by specifying the scenario context, a description, the aspects of play, the authenticity, the immersion, the persistence, etc.

- The discipline management function enables the designer to create, edit, display or delete a new discipline.

- The community management function enables the designer to create, edit, display or delete a new community.

- The JEN.Cards management function allows the designer to manage the categories of the cards, and to create, edit, display or delete a new card.

- The user profile management function enables the designer to create, modify or delete the profiles of the users of the tool (e.g. the teacher, game-designer, administrator).

Our ADDEGames tool and the specification of its technical architecture were designed based on the co-design process and the JEN model. Its development was carried out in several iterations (in agile mode). At the end of each iteration, the teachers participated in the validation of the developed elements and made suggestions for improvements. Fig 10. Illustrates the main interface of ADDEGames tool. 


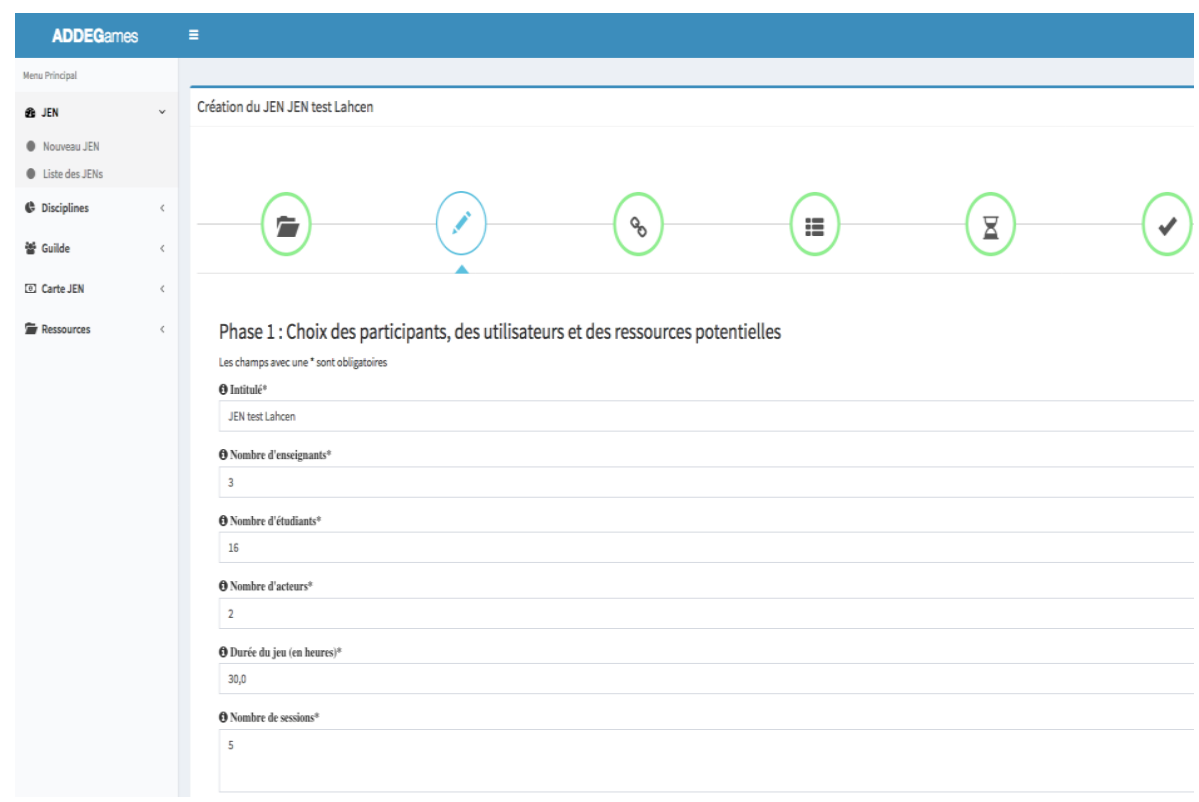

Figure 10. The main interface of ADDEGames[55]

\section{Development and User Testing of ADDEGames}

The ADDEGames tool was designed to support $J E N$ co-designers, and was developed in an iterative and participative way using an agile process [56] with the participation of the teachers and researchers involved in the research project. In each iteration, the participants in the process contributed to the improvement and evolution of the functionalities and interface. Three main iterations were carried out. The process integrates user-centred design and an agile method. User-centred design is a process that involves users on an iterative basis. An agile method is based on an iterative and incremental process in order to better address the user's needs. The development process is sufficiently rapid and flexible to adapt the product to the changes required by the participants in the process. The main objectives of the development process are usability and end-user satisfaction. This process was conducted using the DBR approach, and involving both researchers and practitioners (Section 4.2). The process took place in several iterations of the design, coding and user test phases. In each iteration, user tests were conducted with the participants. In user-centred methods, most of the tasks involve searching for information (on users and their tasks, the context, etc.), design and evaluation. The upstream task at the beginning of the process defines the global vision of the design. In the agile method, a prototype is produced at the end of each iteration and adaptations are made based on an evaluation by the user.

The process took place in three iterations, in which a user test session was conducted at each iteration to allow the evolution of the prototype (Fig. 11). At the beginning of the process, the team produced a paper-based prototype to define the global vision. At the end of each iteration, an executable version of the prototype was developed. We used checklists and review meeting to collect feedback of the participants of the user test session.

The prototype was implemented and delivered by the computer research team and tested by the teachers and researchers playing the role of the product owner (the user representative). The computer research team in charge of development then noted the remarks, questions and proposals put forward during the review meeting. Two use scenarios were proposed: in the first, teachers and researchers taking part in the development process were asked to re-create the JENs Insectophagia and Rearth; in the second, we asked them to navigate and modify or adapt an existing JEN. Teachers and 
researchers were asked when experimenting with the prototype to report any interaction (interface, ergonomic) or functional problems, and this allowed us to create a report on the user testing of the prototype at each iteration of the development.

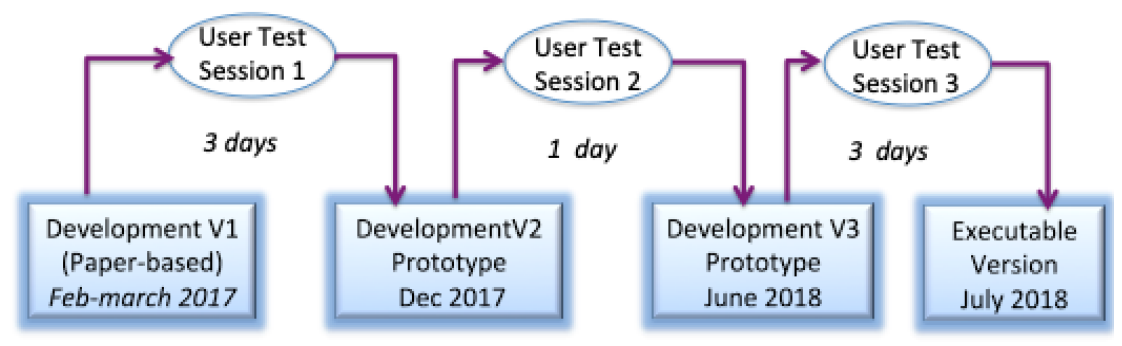

Figure 11. The agile co-design process

We built two teams for the two existing JENs, which were composed of researchers (who had been involved in other parts of the project), teachers (with the expert knowledge needed for each $J E N$ ) and members of the computer research team (who led the user test session for each team). The first user test session last 3 days (in six months) and was carried out involving a representative teacher in charge of the Rearth JEN and 2 members of the computer research team. An executable version of the author tool prototype was available. We tested two scenarios based on the field experience of this teacher (navigate and modify or adapt the existing JEN and create a new JEN). Our objectives were to test the functionality and the ergonomic aspects of the prototype. The main changes that were identified related to the visual aspects of the prototype, such as adding navigation buttons on the design page (as shown in Fig. 12), changing the terminology for some of the basic concepts of the JEN, and adding some tool tips to describe some of the information fields that needed to be completed. Some of the other changes required related to improving or adding functionalities (such as creating an import tool for cards using an Excel spreadsheet, organising the cards better in the final report of the design, improving the navigability in the different design steps, etc.).

During the second user test session (1 day), the first use scenario was tested, in which the two existing JENs were recreated. We asked the two teams (6 researchers and 3 teachers) to simulate the creation of the JEN by following the paper-based JEN design guide we developed to check and validate the design approach.

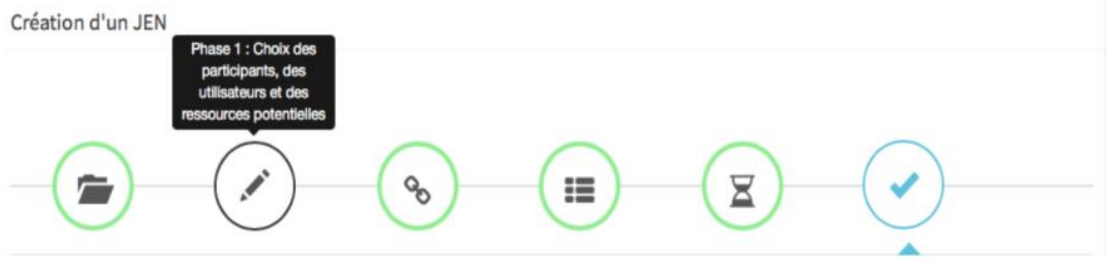

Figure 12. Navigation tool for the design pages

The last iteration was carried out using the new version of the design author tool prototype based on the availability of the teachers and researchers. The same team of the first user test session, and 2 new teachers expert involved for the Insectophagia game participated to this last user test session. This session took place in 3 days between June and July 2018. Changes to the ergonomic aspects and the addition of new functionalities were requested. One of the main changes was the implementation of a new submenu entitled "Resources" to offer different contents presenting the tool, help users to create the $J E N$ and manipulate the design author tool (user guide, example of JEN in PDF format, parameter file of JEN.Cards, parameter file of tooltips, tutorials). 


\section{Conclusion}

One of the main purposes of the JEN.lab project was to study the design process of JENs and to offer methodological and technical tools to help a team of teachers to create a JEN by themselves. In this paper, we present a co-design process and an assistance design tool for JENs called ADDEGames, which is based on the JEN model. The starting point for the development of the JEN model was to identify all the elements necessary to describe an epistemic scenario for integration by the teacher. For this, we rely on the concepts defining the $J E N$ characteristics that we have enriched from case studies of existing JENs, in order to take into account the specific aspects of this pedagogical approach. Our first proposal is a model that can describe JENs independently of the domain and context.

The co-design process and the JEN model were improved during the workshop sessions according to the methodology of the project. Some workshop sessions with teachers and researchers were specifically dedicated to improvements in this process and its supporting environment. The teachers were asked to re-design their games using the game design environment developed by the research team.

We tested ADDEGames using a use case scenario to evaluate its usability and user satisfaction. The protocol and the results of this experiment were presented in section 7 of this paper. The main changes were the possibility to adapt the terminology of a JEN, the addition of notes to in the design steps to explain the concepts of a JEN, and improvements to the navigability through the different parts (steps) of the process.

The results of the acceptance testing were positive. The users of ADDEGames confirmed that the tool allowed them to design JENs and identify the different elements of an epistemic scenario. Users also reported that the visual representation of the modelling steps of a $J E N$ as a workflow facilitated this task (Fig. 12). The teachers appreciated the JEN.Cards, and in particular the paper-based format; however, they reported difficulties in going from this form to the computer-based designing environment, and suggested adding QR codes to the cards that could be read and automatically integrated into the tool.

One of the main problem during the development was the difficulty to identify the needs and requirements of all the actors of JEN (learners, teachers, game designers, ...). We aimed in this project to propose methods and tools that offer them the possibility to design their own needs by themselves. All the JEN.Lab artefacts such as JEN.cards, PMS, $A D D E G a m e s$ was designed in this objective with participative and agile development method. Some difficulties remaining in this kind of project are due to the evaluation of the artefacts proposed.

We are currently trying to encourage wider use of the tools designed during the $J E N . L a b$ project and are collecting feedback on the users' experiences. Some improvements have been already identified, such as the deployment of the last phase of the co-design process. On the basis of previous work and the needs identified in the learning design domain [57][58], we intend to develop a graphic author tool to help the designer team to design a JEN scenario model based on the statement of work developed with ADDEGames. We should then be able to propose some services to operationalise these models in the Play Management System.

\section{References}

[1] "JEN.lab project" http://jenlab.fr/

[2] E. Sanchez. A Model for the Design of Digital Epistemic Games. In N. Reynolds \& M. Webb (Eds.), Proceedings of the X World Conference on Computers in Education (pp. 257-264). Torun, Poland. 2013 
[3] D.W. Shaffer. Epistemic frames for epistemic games. Computers and Education, 46(3), 223-234. Retrieved from http://epistemicgames.org/cv/papers/shaffer_cae_2005.pdf. 2006 https://doi.org/10.1016/j.compedu.2005.11.003

[4] S. Ohlsson. Learning to do and learning to understand: A lesson and a challenge for cognitive modeling. In P. Reiman \& H. Spade (Eds.), Learning in Humans and Machines: Towards an interdisciplinary learning science, 1995, pp. 37-62. Oxford, UK: Elsevier Science.

[5] Y. Mor, B. Craft, and M. Maina. LD : Definitions, Current Issues and Grand Challenges, in The Art \& Science of Learning Design, TEL, Vol.9, 2015.

[6] P. Goodyear. Teaching as design, HERDSA Review of Higher Education, pp. 27-50. 2015

[7] D. Hernandez-Leo, S. Agostinho, M. Beardsley, S. Bennett, and L. Lockyer. Helping teachers to think about their design problem: a pilot study to stimulate design thinking, in 9th annual International Conference on Education and New Learning Technologies EDULEARN17, Barcelona, Spain, 2017 https://doi.org/10.21125/edulearn.2017.2291

[8] S. Bennett, S. Agostinho, and L. Lockyer. The process of designing for learning: understanding university teachers design work, Educational Technology Research and Development, vol. 65, no. 1, p. 125-145, 2017 https://doi.org/10.1007/s11423-016-9469-y

[9] Y. Mor, B. Craft. Learning Design: reflections on a snapshot of the current landscape. Research in Learning Technology, 20 pp. 85-94, https://doi.org/10.3402/rlt.v20i0.19196, 2012 https://doi.org/10.3402/rlt.v20i0.19196

[10] E. Sanchez, S. Young, C. Jouneau-Sion Classcraft from gamification to ludicization of classroom management. Education and Information Technologies, March 2017, Volume 22, Issue 2, pp 497-513, 2017 https://doi.org/10.1007/s10639-016-9489-6

[11] G. Loup, A. Serna, S. Iksal, S. George. Immersion and Persistence: Improving Learners' Engagement in Authentic Learning Situations. In: Verbert K., Sharples M., Klobučar T. (eds) Adaptive and Adaptable Learning. EC-TEL 2016. Lecture Notes in Computer Science, vol 9891. Springer, Cham. p. 410-415. https://doi.org/10.1007/978-3-319-451534_35, 2016

[12] G. Loup, S. George, A. Serna. Fondements et caractérisation des jeux épistémiques numériques pervasifs. S. George, G. Molinari, C Cherkaoui, D. Mammas et L. Oubahssi. 7ème Conférence sur les Environnements Informatiques pour l'Apprentissage Humain (EIAH 2015), Jun 2015, Agadir, Maroc. pp.41-52, 2015.

[13] S. Kirginas, D. Gouscos, "Development and Validation of a Questionnaire to Measure Perceptions of Freedom of Choice in Digital Games," International Journal of Serious Games, $\quad 3(2) . \quad 2016 . \quad$ https://doi.org/10.17083/ijsg.v3i2.120 https://doi.org/10.17083/ijsg.v3i2.120

[14] "Design-Based Research Collective". (2003). Design-based research: An emerging paradigm for educational inquiry. Educational Researcher, 32(1), pp 5-8, 2003 https://doi.org/10.3102/0013189X032001005

[15] W. Sandoval, P. Bell. Design-Based Research Methods for Studying Learning in Context: Introduction. Educational Psychologist, 39(4), pp. 199-201, 2004, https://doi.org/10.1207/s15326985ep3904_1

[16] E. Sanchez, R. Monod-Ansaldi. Recherche collaborative orientée par la conception. Un paradigme méthodologique pour prendre en compte la complexité des situations d'enseignement-apprentissage. Education \& Didactique, 9(2), 73-94, 2015 https://doi.org/10.4000/educationdidactique.2288

[17] F. Wang, M. J. Hannafin. Design-based research and technology-enhanced learning environments. Educational technology research and development, 2005. pp 5-23 https://doi.org/10.1007/BF02504682

[18] E. Sanchez, C. Piau-Toffolon, L. Oubahssi, A. Serna, I. Marfisi-Schottman, G. Loup, and S. George. Toward a Play Management System for Play-Based Learning. In: Verbert K., Sharples M., Klobučar T. (eds) Adaptive and Adaptable Learning. EC-TEL 2016. Lecture Notes in Computer Science, vol 9891. Springer, Cham. p. 484-489. https://doi.org/10.1007/978-3-319-45153-4_47

[19] E. Sanchez. Game-Based Learning. In A. Tatnall (Ed.), Encyclopedia of Education and Information Technologies: Springer Cham, 2019. https://doi.org/10.1007/978-3-31960013-0_39-2

[20] A. Collins, W. Ferguson. Epistemic forms and Epistemic Games: Structures and Strategies

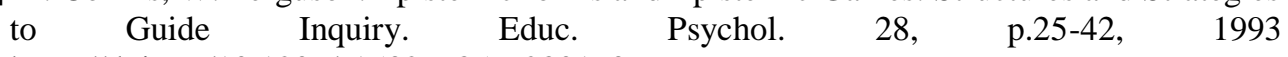
https://doi.org/10.1207/s15326985ep2801_3 
[21] D.N. Perkins: "Epistemic games". International Journal of Educational Research. Volume 27, Issue 1, 1997, Pages 49-61, https://doi.org/10.1016/S0883-0355(97)88443-1

[22] D.W. Shaffer, J.P. Gee. Before Every Child Is Left Behind: How Epistemic Games Can Solve the Coming Crisis in Education. WCER Working Paper No. 2005-7. Wisconsin Center for Education Research, 2005

[23] D. Hatfield, D.W. Shaffer. Press play: Designing an epistemic game engine for journalism. Proceedings of the 7th international conference on Learning sciences. pp. 236242. International Society of the Learning Sciences, 2006

[24] A. Foster, et al. Virtual Learning Environments for Promoting Self Transformation: Iterative Design and Implementation of Philadelphia Land Science. In: Beck D. et al. (eds) Immersive Learning Research Network. iLRN 2018. Communications in Computer and Information Science, vol 840. Springer, 2018. Cham. https://doi.org/10.1007/978-3-31993596-6_1

[25] E. Sanchez, C. Jouneau-Sion, L. Delorme, S. Young, C. Lison, N. Kramar. Fostering Epistemic Interactions with a Digital Game A Case Study about Sustainable Development for Secondary Education. International Symposium Science \& Technology Education for Development, Citizenship and Social Justice, 2012

[26] D.W. Shaffer, D. Hatfield, G.N. Svarovsky, P. Nash, A. Nulty, E. Bagley, K. Frank, A.A. Rupp, R. Mislevy. Epistemic Network Analysis: A Prototype for 21st-Century Assessment of Learning. Int. J. Learn. Media 1, 33-53, 2009 https://doi.org/10.1162/ijlm.2009.0013

[27] E. Sanchez, N. Kramar, C. Lison. Playing with geomedia to understand the complexity of the world. In T. Jekel, E. Sanchez, I. Gryl, C. Jouneau-Sion, \& J. Lyon (Eds.), Learning \& Teaching with Geomedia (pp. 200-207). London: Cambridge Scholars, 2014

[28] MA. Salmani-Nodoushan. The Shaffer-Gee perspective: Can epistemic games serve education?. Teaching and Teacher Education. 25. 897-901. 10.1016/j.tate.2009.01.013, 2009 https://doi.org/10.1016/j.tate.2009.01.013

[29] P.M. King, K.S Kitchener. Developping Reflective Judgement: Understanding and Promoting Intellectual Growth and Critical Thinking in Adolescents and Adults. San Francisco, CA: Jossey-Bass Publishers, 1994

[30] M. Brabeck, P. Wood. Cross-sectional and longitudinal evidence for differences between well-structured and ill-structured problem solving abilities. Adult development (2), 133146,1990

[31] M. Baker. Argumentation and Constructive Interaction. In P. Coirier \& J. Andriessen (Eds.), Foundations of Argumentative Text Processing (Vol. Vol. 5, pp. 179-202). Amsterdam, NL University of Amsterdam Press, 1999

[32] P. Milgram, F. Kishino. A taxonomy of mixed reality visual displays. IEICE (Institute of Electronics, Information and Communication Engineers) Transactions on Information and Systems, Special issue on Networked Reality (77), 1321-1329, 1994

[33] J. Henriot. Le jeu. Paris: Presses Universitaires de France, 1969

[34] B. Suits. Grasshopper: Games, Life and Utopia. Boston: David R. Godine, 1990

[35] K. Salen, E. Zimmerman. Rules of play, game design fundamentals. Cambridge, MA: MIT Press, 2004

[36] B. Marne, J-M. Labat. Model and Authoring Tool to Help Teachers Adapt Serious Games to their Educational Contexts. IJLT [En ligne],.Vol. 9, $\mathrm{n}^{\circ} 2$, p. 161-180, 2014 https://doi.org/10.1504/IJLT.2014.064491

[37] R. Garris, R. Ahlers, J.E. Driskell. Games, motivation, and learning: A research and practice model. Simulation \& Gaming, 33(4), 441-467, 2002 https://doi.org/10.1177/1046878102238607

[38] E. Sanchez, M. Plumettaz-Sieber. Teaching and Learning with Escape Games From Debriefing to Institutionalization of knowledge. In M. Gentile, M. Allegra, \& H. Söbke (Eds.), 7th International Conference, GALA 2018, Palermo, Italy, December 5-7, 2018, Proceedings (Vol. 11385, pp. 242-253): Springer International Publishing. https://doi.org/10.1007/978-3-030-11548-7_23

[39] Y. Deng, A.N. Antle, C. Neustaedter. Tango cards: a card-based design tool for informing the design of tangible learning games. ACM Press, pp. 695-704, 2014 https://doi.org/10.1145/2598510.2598601

[40] N.K. Boots, J. Strobel, Equipping the Designers of the Future: Best Practices of Epistemic Video Game Design. Games Cult, 2014 https://doi.org/10.1177/1555412014536631 
[41] A. Serna, A. Tabard, V. Emin-Martinez. JEN.Cards : un outil pour faciliter la conception collaborative de learning games, in: Proceedings of the JEN Workshop, EIAH Conference, 2015.

[42] N. Cross. Designerly ways of knowing. London: Springer-Verlag, 2006

[43] G. Goldschmidt. Creative architectural design: Reference versus precedence. Journal of Architectural and Planning Research, 15(3), 258-270, 1998

[44] R. Cober E. Tan, J. Slotta, H-J So, Kd. Könings. Teachers as participatory designers: two case studies with technology-enhanced learning environments. Instructional Science. 10.1007/s11251-014-9339-0, 2005

[45] Y. Mor, N. Winters. Design approaches in technology enhanced learning , Journal of Interactive Media in Education, 2007 https://doi.org/10.1080/10494820601044236

[46] P. Cottier, C. Choquet. De l'usager construit à l'usager participatif. EIAH Montpellier 2527 mai 2005, p. 449-454.

[47] P. Cobb, J. Confrey, A. diSessa, R. Lehrer, L. Schauble. Design experiments in educational research. Educational Researcher,(32), 9-13. 2003 https://doi.org/10.3102/0013189X032001009

[48] D. Schuler, A. Namioka. Participatory Design: Principles and Practices. P. Hillsdale: Lawrence Earlbaum Associates. 1993

[49] J. Highsmith. Agile software development ecosystems. Boston, MA: Addison-Wesley Professional. 2002

[50] D. Norman, S. Draper. (1986). User Centered System Design: New Perspectives in Human-Computer Interaction. Hillsdale, N.J: Lawrence Erlbaum Associates. https://doi.org/10.1201/b15703

[51] "The game scenarios" The scenarios are available at http://www-lium.univlemans.fr/legadee/app/bin-debug/PageAccountManagement.html

[52] I. Marfisi-Schottman, S. George, F. Tarpin-Bernard. Tools and Methods for Efficiently Designing Serious Games, Proceedings of the European Conference on Games Based Learning, ECGBL, Copenhagen, Denmark, pp. 226-234, 2010

[53] L. Oubahssi, G. Loup, C. Piau-Toffolon, O. Mahdi. ADDEGames: An Assistance Design tool for Digital Epistemic Games. The 18th IEEE International Conference on Advanced Learning Technologies IIT Bombay, India Jul 09th - Jul 13th 2018. https://doi.org/10.1109/ICALT.2018.00031

[54] "Characteristics of a JEN and the Design Phase" http://jenlabfr/resultats/12-3-1-tableau-decaracterisation-dun-jen

[55] "Assistance Design tool for Digital Epistemic Games". To test the tool, go to https://laaddegames.univ-lemans.fr/login (Username $=$ test $/$ Password $=$ test)

[56] D. Deuff, M. Cosquer, B. Foucault. Méthode centrée utilisateurs et développement agile : une perspective gagnant-gagnant" au service des projets de R\&D, IHM10, Luxembourg 20-23 sept. 2010, pp. 189-196. https://doi.org/10.1145/1941007.1941041

[57] A. Bakki, L. Oubahssi, S. George, C. Cherkaoui. MOOCAT. A Visual Authoring Tool in the cMOOC Context. Education and Information Technologies, Springer Verlag, In press. P.1-25. 2018. ISSN 1573-7608. DOI: https://doi.org/10.1007/s10639-018-9807-2 https://doi.org/10.1007/s10639-018-9807-2

[58] O. Mahdi, L. Oubahssi, C. Piau-Toffolon, S. Iksal. A model and its tool to assist the scenarization of VR-oriented pedagogical activities. The 11th International Conference on Computer Supported Education, Crète, Greece, 2-4 may 2019 http://insticc.org/node/TechnicalProgram/csedu/presentationDetails/77619 https://doi.org/10.5220/0007761905110518 